\title{
EXPANDINDO O CONCEITO DE LETRAMENTO
}

\author{
EXPANDING THE CONCEPT OF LITERACY*
}

\author{
ELIZABETH DALEY $Y^{* * * * *}$
}

\begin{abstract}
RESUMO: Este artigo apresenta e discute quatro argumentos para expandir a definição de letramento, a saber: (1) a linguagem multimidiática da tela se transformou no vernáculo corrente; (2) a linguagem multimidiática da tela é capaz de construir significados complexos independentemente do texto; (3) a linguagem multimidiática da tela permite modos de pensamento, formas de comunicar e produzir pesquisa, e métodos de publicação e de ensino que são essencialmente diferentes daqueles relacionados ao texto; (4) serão realmente letrados no século 21 aqueles que aprenderem a ler e escrever a linguagem multimidiática da tela.
\end{abstract}

Palavras chave: multimídia; linguagem de tela; letramento.

ABSTRACT: This paper presents and discusses four arguments to expand the definition of literacy as follows: (1) the multimedia language of the screen has become the current vernacular; (2) the multimedia language of the screen is capable of constructing complex meanings independent of text; (3) the multimedia language of the screen enables modes of thought, ways of communicating and conducting research, and methods of publication and teaching that are essentially different from those of text; (4) those who are fully literate in the twenty-first century will be those who learn to both read and write the multimedia language of the screen.

Keywords: multimedia; language of screen; literacy.

Quando peço para as pessoas definirem, em poucas palavras, o conceito de letramento - o que é letramento e o que o letramento permite às pessoas fazerem - as respostas que recebo são bem semelhantes. Para a maioria delas, letramento significa ter a habilidade de ler e escrever, entender informações e expressar ideias de maneira concreta e abstrata. $\mathrm{O}$ pressuposto não explicitado é que "ler e escrever" significa ler e escrever texto. Apesar dos letramentos midiático e computacional serem ocasionalmente mencionados nessas definições, o midiático é frequentemente definido como a habilidade de compreender como

* Original em inglês disponível em http://net.educause.edu/ir/library/pdf/ffpiu027.pdf (Acesso em $30 / 07 / 2010)$.

** Agradecimentos das organizadoras a Joel W Meyerson (Forum for the Future of Higher Education and EDUCAUSE) pela mediação na obtenção da licença para tradução.

*** Diretora Executiva do Annenberg Center for Communication e reitora da Escola de Cinema e Televisão da University of Southern California (USC). Doutora em arte da comunicação pela Universidade de Wisconsin. Esse artigo foi elaborado a partir de uma comunicação apresentada no Fórum para o Futuro da Educação Superior, Aspen, 2002. 
a televisão e o cinema manipulam os espectadores, e o letramento computacional como as habilidades para usar um computador na realização de várias tarefas como, por exemplo, acessar a Web. E se eu pergunto para as pessoas sobre a natureza da linguagem, geralmente respondem que a linguagem nos permite conceitualizar ideias, abstrair informação, receber e compartilhar conhecimento. O pressuposto subjacente, tão aceito que nem é explicitado, é o de que linguagem significa palavras.

Há vinte e cinco anos, um livro bem popular tinha como título: Quatro argumentos em favor da eliminação da TV [Four Arguments for the Elimination of Television]. É claro que aquela ideia sobre o mundo sem televisão não se concretizou: a televisão não foi eliminada, e as telas - de televisões e computadores - agora dominam nossas vidas. Essa realidade precisa ser reconhecida. Então, seguindo o espírito do título desse livro que acabo de mencionar, eu gostaria de sugerir quatro argumentos para se expandir a definição de letramento:

1. A linguagem multimidiática da tela se transformou no vernáculo corrente.

2. A linguagem multimidiática da tela é capaz de construir significados complexos independentemente do texto.

3. A linguagem multimidiática da tela permite modos de pensamento, formas de comunicar e produzir pesquisa, e métodos de publicação e de ensino que são essencialmente diferentes daqueles relacionados ao texto.

4. Por último, seguindo os três argumentos anteriores, serão realmente letrados no século 21 aqueles que aprenderem a ler e escrever a linguagem multimidiática da tela.

Essas quatro afirmações são os princípios fundamentais do trabalho que está sendo feito no Instituto para o Letramento Multimidiático (IML) no Centro Annenberg da University of Southern California (USC).

\section{A LINGUAGEM MULTIMIDIÁTICA DA TELA SE TRANSFORMOU NO VERNÁCULO CORRENTE}

Frequentemente, peço a meus colegas para imaginarem que estão vivendo e lecionando em Pádua por volta do ano 1300. Dentro dos muros de pedra daquela grande universidade, eles ensinam em latim, mas as pessoas que andam pelas ruas abaixo de suas janelas, incluindo os seus próprios alunos, falam italiano. Em algum momento, essa língua vernácula tem que ser incluída (e, na verdade, ela foi) na Academia Italiana. Colocado de forma simples, o argumento correspondente hoje é que para a maioria das pessoas - incluindo alunos - os filmes, a televisão, o computador, os jogos online e as músicas constituem o vernáculo corrente.

A palavra impressa permitiu primeiramente o letramento de pessoas comuns, e foi muito eficaz, mas privilegiar uma linguagem impressa significa ignorar o sucesso de outras tecnologias - gravação em áudio, rádio, cinema e televisão - que passaram a existir desde os primórdios da impressão da escrita. Essas tecnologias se tornaram, para os cidadãos médios, os modos mais comuns de receber informação, de se comunicar uns com os outros 
e de se divertir. Não é difícil perceber como a gramática dessas tecnologias há muito invadiu o nosso pensamento coletivo. As metáforas da tela se tornaram comuns nas falas cotidianas. Por exemplo, dar um close [close-up] é sinônimo de "verticalizar" e "aprofundar". Nós nos referimos a flashback como um olhar voltado para o passado. Nós enquadramos [frame] eventos para contextualizá-los. Nós usamos a palavra corta [cut] quando estamos com pressa, dissolve [dissolve], fade out ou segue [segue] quando queremos passar de um tópico para outro e usamos também background sonoro (som de fundo). Passamos muitas horas em nossos computadores olhando e compartilhando telas. Os alunos estão acostumados com a experiência direta da música como um dos fatores primários para a criação da identidade deles e passam horas jogando no computador em comunidades online. Para resumir, as experiências compartilhadas com os outros seres humanos são, na maioria das vezes, derivadas das imagens e sons contidos nas telas.

\section{A LINGUAGEM MULTIMIDIÁTICA DA TELA É CAPAZ DE CONSTRUIR SIGNIFICADOS COMPLEXOS, INDEPENDENTEMENTE DO TEXTO}

Na USC, a renomada Escola Superior de Cinema e Televisão é elogiada, invejada e admirada, mas ainda desperta dúvidas. No mundo acadêmico continua sendo vista como uma anomalia. Não serve de parâmetro para ranqueamento nacional de nenhuma universidade, nem tem a mesma importância que os departamentos de Física ou de Inglês.

Acredito que a razão para essa falta de prestígio não é somente porque criadores de mídia e scholars lidam com esse "desacreditado" mundo do entretenimento, mas também, o que é mais importante ainda, porque em seu trabalho nessa área eles não dão primazia à palavra impressa. Eles acreditam que imagens e sons, integrados em um meio cronometrado [time-based], podem ser tão importantes para criar conhecimento e comunicar ideias quanto passar informações por meio de textos escritos. Em nível mais fundamental, o trabalho deles não endossa a premissa, amplamente aceita nos últimos dois milênios, de que a compreensão e a expressão em material impresso definem o que é ser letrado e por extensão o que é ser educado.

Há uns anos atrás, um colega me enviou um artigo que tinha aparecido na Chronicle of Higher Education. O autor, um respeitado historiador de arte, afirmava que já era hora da academia abandonar a arraigada reserva em relação às imagens e perceber que o visual pode de fato conter conteúdo intelectual, o qual pode em alguns casos ser igual ao do texto escrito. Presumi que o artigo era uma reimpressão e que talvez tivesse sido escrito nos anos 1930, mas era contemporâneo. Naquele momento, eu percebi que nós do Institute for Multimedia Literacy precisaríamos defender não somente a ideia de um vernáculo que fosse uma linguagem de base cinemática/ multimidiática, mas também, e o mais importante, defender o valor dessa ideia. Tínhamos um caminho longo a percorrer para mostrar que tal linguagem pode ter diferenças claras e até vantagens em relação à linguagem impressa, em alguns casos.

Ao argumentar a favor da importância da linguagem da tela, não pretendo ir contra palavras ou impressos. Mas, a palavra impressa carrega seu próprio viés tecnológico. Ela comporta argumento linear, mas não valoriza aspectos da experiência que não possam ser 
incorporados em livros. A palavra escrita lida de forma inadequada com modos não verbais de pensamento e construção não linear.

Como texto, a multimídia pode nos permitir desenvolver conceitos e abstrações, comparações e metáforas, envolvendo ao mesmo tempo nossas sensibilidades emocionais e estéticas. Uma mídia diversificada, com suas camadas múltiplas e simultâneas, faz muito mais do que fornecer realces, ilustrações e instrumentos para enriquecer, dar acesso e transmitir as formas do letramento estabelecido. Pense um pouco nas imagens fixas que definiram muitos momentos importantes na história dos Estados Unidos: os ensaios fotográficos da Grande Depressão; um marujo beijando uma moça em Times Square no final da Segunda Guerra Mundial; uma jovem vietnamita fugindo de bomba napalm; uma universitária de Kent State debruçando-se sobre um corpo. Como ícones, essas imagens não mais necessitam de nenhuma explicação para a maioria dos americanos contemporâneos, apesar de que um texto escrito, ou uma explicação oral, possa bem complementar e ampliar seus significados. No entanto, mesmo que não conhecêssemos seus contextos de criação, cada uma dessas imagens carregaria significados fortes e transmitiria poderosas emoções. A multimídia e o cinema, apesar de muitas vezes enriquecidos pela linguagem verbal, abraçam muitos outros elementos de igual poder - não somente imagens, mas também som, duração, cor e design. Pense também um pouco sobre históricos momentos cinemáticos como: a primeira aterrissagem na Lua ou os aviões abalroando o World Trade Center. Como seria tentar compartilhar plenamente tão importantes acontecimentos sem ter acesso à linguagem e ao poder da tela?

\section{A LiNGUAGEM MULTIMIDiÁtiCA DA TELA PERMITE MODOS DE PENSAMENTO, FORMAS DE COMUNICAR E PRODUZIR PESQUISA, E MÉTODOS DE PUBLICAÇÃO E DE ENSINO QUE SÃO ESSENCIALMENTE DIFERENTES DAQUELES RELACIONADOS AO TEXTO}

Desde o Iluminismo, a comunidade intelectual tem valorizado o racional em detrimento do afetivo, o abstrato em detrimento do concreto, o descontextualizado em detrimento do contextualizado. Esses valores, combinados com uma desconfiança profundamente arraigada em relação à prática e à criação de produtos, tornam difícil trazer o vernáculo da mídia contemporânea para o mundo acadêmico.

Aceitar a linguagem multimidiática como tão importante quanto o texto escrito vai requerer uma significativa mudança de paradigma, que desafie a dominação da ciência e da racionalidade, da abstração e da teoria. Certamente não estou sozinha quando penso que essa mudança já deveria ter acontecido há muito tempo. Por exemplo, Stephen Toulmin, em Cosmópolis [Cosmopolis], seu livro muito conhecido, de 1990, argumentou eloquentemente que o mundo acadêmico deveria superar o domínio do modelo cartesiano. Mas somente uns anos atrás é que percebi quão difícil seria essa transição, quando uma acadêmica senior explicitou porque achava difícil julgar o mérito de artistas para promoção e carreira. Ela disse que achava os trabalhos deles específicos demais e sem base abstrata, ou teórica. A impressão que ficou foi que um professor que escreve sobre arte é mais valorizado que aquele que a produz. 
A linguagem multimidiática é, sem dúvida, muito mais relacionada ao afetivo e à linguagem subjetiva da arte do que à linguagem linear e racional da ciência. Sergei Eisenstein, o grande cineasta russo, certa vez descreveu a linguagem da arte como oposta à científica, como uma linguagem do conflito, uma linguagem dialética em oposição a uma linguagem linear. Quando a linguagem da ciência é aplicada à arte, argumentou o autor, ela a fossiliza. Por exemplo, uma paisagem se transforma em um mapa topográfico e uma pintura de São Sebastião vira um estudo anatômico ${ }^{1}$.

A gramática da multimídia e os modos com que ela cria significado estão apenas começando a ser articulados sistematicamente. Por outro lado, a linguagem do cinema nos oferece um extenso corpo teórico, que pode nos fornecer um ponto de partida para se pensar sobre multimídia. Em 1923, Dziga Vertov, cineasta soviético de documentários e um dos pioneiros russos da linguagem cinemática, escreveu um pitoresco monólogo para uma filmadora que poderia muito bem ser aplicado para a multimídia hoje:

Sou um olho mecânico, sou uma máquina, mostro a você um mundo de um modo que somente eu posso ver. Agora e para sempre, eu me liberto da imobilidade humana. Estou em constante movimento. Eu me aproximo e me distancio dos objetos... gravando movimento... das mais complexas combinações. Liberto dos limites de tempo e espaço, coloco juntos quaisquer pontos no universo, não importa onde eu os tenha gravado. ... O meu caminho leva à criação de uma percepção nova do mundo. Eu decifro, de um modo novo, um mundo desconhecido para você. ${ }^{2}$

Uma das pedras fundamentais da cinemática, que também se aplica a grande parte da multimídia, é a montagem ou justaposição de elementos, tanto dentro quanto entre tomadas. Para o cineasta, esta é a arte de edição e é o cerne para a criação no cinema. A montagem oferece um exemplo claro e importante de como o texto verbal e o multimidiático constroem significados de formas distintas. Por meio da montagem, você é capaz de manipular o tempo e o espaço e criar sequências que nunca existiram no mundo físico e real, mas que são tematicamente e conceitualmente relacionadas. A montagem permite uma interação entre $o$ criador e o receptor, como também entre os elementos da criação. Ela permite e encoraja a recombinação dos elementos da natureza para criar novos significados.

A famosa demonstração de montagem de Lev V. Kuleshov, mais um dos pioneiros russos, elucida esse conceito. Kuleshov fez um curta sequência em que justapôs a face de um famoso ator russo sobre três diferentes tomadas: uma tigela de sopa, uma mulher morta dentro de um caixão, e uma menina brincando com um urso de pelúcia. Quando perguntados sobre o que tinham visto, os espectadores - de acordo com V. I. Pudovkin, que era na época um aluno de uma das oficinas de Kuleshov - insistiam que o homem estava faminto quando olhava para a sopa, feliz quando olhava para a menina e triste quando olhava para a mulher morta. Eles descreviam detalhadamente suas várias emoções, como prova do grande talento do ator. Todas as versões eram, no entanto, a mesma tomada do ator. Nada na sua imagem havia sido mudado. O significado atribuído veio somente da montagem das tomadas.

Com o computador, nós podemos agora, eletronicamente, construir imagens e sons e podemos manipular o espaço e o tempo para criar significados de tal forma que nossos

\footnotetext{
${ }^{1}$ Eisenstein, 1957, p. 46.

${ }^{2}$ Michelson, 1984, p. 17-18.
} 
progenitores russos só poderiam sonhar. As ferramentas de ajuste, composição e formatação são mais do que modos de mal representar a verdade. Essas ações nos permitem a construção de ordens superiores de significado, nuance e inferência. As possibilidades de síntese e de recorte, assim como a simultaneidade, são ações naturais para a multimídia, permitindo uma forma de bricolagem, um processo pelo qual, nas palavras de John Seely Brown, uma pessoa pode "encontrar alguma coisa (talvez uma ferramenta, algum código aberto, imagens, música, texto) que pode ser usada ou transformada para a construção de algo novo.

A interatividade, como um fator fundamental na multimídia, está de certo modo muito relacionada à performance, dando oportunidade ao espectador/leitor/usuário de participar diretamente na construção do significado. Talvez, valesse a pena fazer uma digressão por um momento para observar que enquanto a performance foi há muito desvalorizada como "entretenimento", a arte de contar histórias, sempre performativa, tem sido a principal forma de transmitir cultura e valores ao longo da história.

Mesmo o vocabulário da multimídia encoraja abordagens distintas daquelas utilizadas para escrever textos. "Cria-se" e "constrói-se" mídia ao invés de escrevê-la, e "navega-se" em e "explora-se" mídia ao invés de lê-la. O processo é ativo, interativo e, frequentemente, social, permitindo muitos pontos de vista.

As técnicas de produção física usadas para se fazer multimídia e as práticas para distribuí-la também se diferenciam dos modelos utilizados para se produzir e publicar textos. Em primeiro lugar, e talvez o ponto mais importante, a produção de multimídia é, na maioria das vezes, um ato de colaboração. Um filme, de curta ou longa duração, é raramente feito por uma só pessoa. Os créditos de um filme são muito frequentemente a manifestação de uma prática comercial específica e não refletem a real natureza da autoria ou do processo de criação. Esse processo colaborativo em projetos multimidiáticos pode ser reduzido em escala, mas é ainda típico. Está na própria natureza do processo criativo e não muda fundamentalmente por motivos de dificuldade ou simplicidade das ferramentas envolvidas.

Em segundo lugar, o produto final - seja ele um filme, um programa de televisão ou outra forma de produção multimidiática - é mais bem sucedido quando emerge em grande parte durante o processo de criação. Um script, ou um cenário ou um storyboard [roteiro desenhado] serve como guia, mas se alguém quer ir além do previsível e do formulaico, deve haver espaço para descoberta e mesmo serendipidade [serendipity] durante a produção ou criação de um filme ou documento multimidiático. Um dos grandes cineastas estadunidenses, Walter Murch, que editou o Paciente Inglês, entre outros filmes conhecidos, refere-se a esse processo como a "colisão de inteligências", cujo produto não pode ser previsto pela equipe de criação, um processo que permite e respeita a intuição. De certa forma, esse processo se constitui num tipo de pesquisa ativa na qual se estuda o que se está fazendo enquanto se está fazendo. Tal trabalho requer um ambiente aberto para a experimentação e uma disposição para explorar e errar - uma "ecologia de experimentação", tomando emprestado uma expressão de um documento da University of Michigan. Esse procedimento permite iterações rápidas e mudanças rápidas de orientação.

E em terceiro lugar, formas midiáticas são geralmente voltadas para apresentação e distribuição pública. São feitas para serem vistas em contextos que vão além daqueles em que são produzidas. No começo, aqui no Institute for Multimedia Literacy, tanto os alunos quanto nós, os professores, achávamos que os projetos dos alunos eram privados e feitos 
para serem vistos apenas por aquele aluno e aquele professor. Contudo, nos últimos semestres, notamos uma mudança em relação à natureza da autoria. Os alunos não mais escrevem para agradar apenas ao professor. Eles querem ser compreendidos por seus colegas e por outros que irão ver e ter a experiência de seus projetos. Eles se consideram autores que possuem expertise numa determinada área. Da mesma forma, a equipe docente tem como objetivo nas oficinas do Instituto disponibilizar seus próprios projetos para os que não cursam suas disciplinas. Equipes de humanas, artes e ciências em geral - disciplinas diversas, desde física quântica até história da arte e filosofia - têm encontrado um campo comum, novas ideias e pontos de acesso para questões pedagógicas e questões de pesquisa nas disciplinas uns dos outros. Certamente, nem todo o trabalho em uma disciplina será compreensível para aqueles que não tem preparo anterior [training], mas para o trabalho interdisciplinar, a equipe docente precisa encontrar uma linguagem que atravesse as fronteiras. A multimídia pode muito bem ter o potencial para oferecer um novo espaço muito necessário, no qual a conversação transdisciplinar possa ocorrer entre as humanidades e as ciências.

\section{POR ÚLTIMO, SEGUINDO OS TRÊS ARGUMENTOS ANTERIORES, SERÃO REALMENTE LETRADOS NO SÉCULO 21 AQUELES QUE APRENDEREM A LER E ESCREVER A LINGUAGEM MULTIMIDIÁTICA DA TELA}

Depois de um século, a linguagem do cinema se encontra até que bem definida, e um grande acervo de literatura crítica já se formou. As metodologias de produção são muito bem compreendidas e articuladas, apesar do conhecimento ainda se apoiar fundamentalmente na cultura oral da comunidade de produção cinematográfica. Mesmo com esse histórico e ampla evidência da habilidade exigida para se construir mídia, a atitude comumente tomada tanto pelo corpo docente quanto pela administração é que textos midiáticos complexos não merecem tempo de aula ou pesquisa, especialmente se tais atividades tirarem a ênfase de atividades tradicionais, como produção de ensaios e artigos de pesquisa.

Desde os anos 1960, universidades e faculdades, e até os colégios de ensino médio, têm ministrado cursos denominados cursos de letramento midiático ou visual. Esses cursos, no entanto, têm tido duas limitações. A primeira é que frequentemente eles parecem ter o pressuposto de que televisão, cinema e as mídias relacionadas são formas inferiores de comunicação que podem representar mal a realidade, pois a mídia, na melhor das hipóteses, nos manipula e mente para nós; e na melhor, é superficial. Esses cursos, até onde eu consigo ver, reforçam a crença de que a educação genuína está nos livros e de que o conhecimento verdadeiro é racional e linear. Os alunos são levados a ler textos visuais para se defenderem do massacre da cultura visual. A segunda limitação está relacionada ao fato desses cursos terem sido extremamente unilaterais na definição de letramento, focalizando uma abordagem de "só leitura" [read only approach]. Um letramento completo requer a habilidade de escrever e também de ler. Recentemente, um renomado scholar me disse que as imagens são menos úteis que os textos, porque imagens podem ser interpretadas de muitas maneiras, mas palavras são muito mais precisas. Eu fiquei pensando se ele nunca 
teria passado pela experiência que a maioria de nós tem no cotidiano - aquela de dizer: "Não, o que eu realmente quis dizer foi..."

A situação atual é mais complicada ainda pela ideia muito difundida de que os alunos já têm um bom conhecimento sobre a linguagem da tela e sobre multimídia. Sem dúvida, os jovens de hoje têm menos medo do computador e mais habilidade técnica com software de mídia diversificada; a multimídia é de fato a linguagem cotidiana deles. No entanto, eles não têm mais habilidade crítica com essa linguagem do que os mais velhos que eles - talvez menos. Eles precisam aprender a escrever para a tela e a analisar multimídia, tanto, senão mais, do que precisam escrever e analisar qualquer gênero textual específico. Geralmente, tiveram algum tipo de instrução sobre texto no secundário, mas raramente receberam instrução similar para multimídia. A multimídia, tão onipresente na experiência dos jovens, muitas vezes parece particularmente difícil de ser analisada ou desconstruída por eles.

Uma outra consideração a ser feita é que apesar do estudo acadêmico sobre cinema, mídia e cultura audiovisual terem estabelecido precedentes pedagógicos que dão insumos teóricos para análise crítica de cinema, televisão e multimídia na educação superior, é comum ver-se mídia integrada em disciplinas curriculares sem o uso dessas importantes ferramentas críticas. Os filmes ou segmentos de filmes são projetados nas mais diversas aulas para "envolver os alunos" com o conteúdo. Frequentemente, esse uso parece ocorrer sem um olhar apropriado para a natureza da mídia audiovisual, seu significado e estrutura inerentes, seu contexto de criação ou as consequências de sua dissecção.

Os exemplos mais salientes desse tipo de prática ocorreram durante as últimas duas décadas em departamentos de história, em que filmes tornaram-se uma parte integrante dos currículos. Apesar da resistência inicial, os filmes de narrativa dramática são agora reconhecidos por sua capacidade de dar "vida" ao passado, criando um impacto emocional que se acredita poder ir além dos textos escritos. No entanto, a maior parte do corpo docente de história e de humanidades não é treinada para trabalhar com os códigos retóricos e as estratégias narrativas de cinema. Assim sendo, os filmes históricos são frequentemente analisados de modo empírico e são avaliados de acordo com os mesmos critérios utilizados para documentos históricos convencionais. Sem um background sobre teoria cinematográfica e sobre linguagem da tela, alunos e professores não lêem um filme como o produto de sistemas de significação altamente desenvolvidos, constitutivos de um contexto cultural. No entanto, eles aprenderam essas habilidades para narrativas textuais desde os estágios iniciais do aprendizado de leitura.

Para ler ou escrever a linguagem da mídia e para entender como ela cria significado em contextos específicos, é preciso algum conhecimento de composição em frames, paleta de cor, técnicas de edição, relação entre som e imagem, assim como a mobilização de convenções narrativas e de gênero, e ainda o contexto de signos e imagens, o som como um veículo do significado, e os efeitos da tipografia. Princípios como direção de tela, enquadramento de objetos, escolhas de cores, formatação, cortes e dissoluções [dissolves], todos juntos fazem muito mais do que uma comunicação visual esteticamente agradável. Esses elementos são estratégicos para a construção do significado, assim como advérbios, adjetivos, parágrafos, orações, analogias e metáforas o são para textos. A multimídia também pede que atenção seja dada ao design, à navegação e à construção de interface. $\mathrm{O}$ mouse, o 
click, o link e as bases de dados já têm seu lugar ao lado de descritores de tela mais tradicionais.

Fora das escolas de cinema, o ensino desses elementos formais de multimídia e de construção cinemática não é dado nos mesmos moldes do ensino de inglês ou de línguas estrangeiras. Na verdade, mesmo o conhecimento mais superficial sobre mídia não é incluído nos currículos de educação geral da maior parte das faculdades ou universidades. As instituições de ensino superior exigem que seus alunos aprendam não somente o que autores como Steinbeck, Hemingway, e Frost escreveram, mas também que entendam suas técnicas o suficiente para discutir tanto o conteúdo de seus trabalhos quanto seus estilos de criação, à luz da teoria literária convencional. Esse tipo de trabalho é dificilmente exigido quando se trata de qualquer tipo de mídia. Na melhor das hipóteses, um curso nas "artes" pode ser exigido, mas dificilmente teria o mesmo peso de um curso em laboratório de línguas.

No Institute for Multimedia Literacy nosso compromisso é o de empoderar professores e alunos para escolherem a melhor linguagem para suas tarefas. Em alguns casos, essa linguagem pode muito bem ser o texto linear e, em outros casos, pode ser um ou mais tipos de multimídia. Para fazer tal escolha, um professor ou aluno deve ter domínio dos elementos da linguagem multimidiática e da tela e deve entender como usar esse domínio para criar e disseminar conhecimento.

\section{O INSTITUTO PARA LETRAMENTO MULTIMIDIÁTICO (IML)}

Meu trabalho com letramento multimidiático começou há alguns anos quando um dos mais famosos ex-alunos da Escola de Cinema e Televisão, George Lucas, me fez uma pergunta muito instigante. "Você não acha", ele disse, "que na próxima década, vai ser preciso ensinar os alunos a ler e a escrever linguagem cinemática, a linguagem da tela, a linguagem do som e da imagem, assim como hoje se ensina a ler e a escrever textos? Caso contrário, não serão eles iletrados como eu e você teríamos sido, se ao sair da faculdade não fôssemos capazes de ler e escrever um ensaio?"

Enquanto eu voava de volta a Los Angeles, naquele dia, percebi que ele estava correto. O que eu não compreendi totalmente, a 25.000 pés sobre o Pacífico, foi que o que ele havia sugerido tão casualmente viria a ser tão perturbador no meio acadêmico. Naquela época, eu era muito nova na universidade e supus que a proposta despertaria considerável interesse dos colegas. Entretanto, quando eu chamei um membro conceituado do departamento de inglês para sugerir que explorássemos caminhos para incorporar o ensino de algumas técnicas básicas de escrita multimidiática em aulas de redação para alunos ingressantes, fui recebida com um profundo silêncio.

Meus colegas, na Escola de Cinema, por outro lado, apoiaram fortemente a ideia, e, no outono de 1998, demos início ao que se transformaria no Instituto para Letramento Multimidiático do Annenberg Center (University of Southern California). Começamos com um curso em que os alunos que não eram da área de cinema deveriam criar um projeto multimidiático na disciplina de sua área de origem, que tivesse o rigor intelectual esperado para um trabalho de final de curso de cinco a sete páginas, e que pudesse ser "explorado" (lido) somente na tela do computador. Esse projeto multimidiático não poderia ser impresso 
em papel. Teria que utilizar som e imagem; teria que ser cronometrado [time-based]; e teria que ser interativo. Não é preciso dizer que todos nós achamos essa tarefa desafiadora. Esses primeiros alunos eram das áreas de antropologia, história, sociologia e literatura inglesa.

Hoje em dia, supervisionamos aulas que incorporam o trabalho com letramento multimidiático na graduação da USC, assim como aulas satélite em Berkeley e Cal Tech, e em mais duas escolas secundárias na região de Los Angeles. A cada semestre, oferecemos a um grupo de professores a oportunidade de participar pela primeira vez do nosso programa, enquanto os demais, já participantes, continuam a trabalhar conosco. Até o momento, mais de dois mil alunos e quarenta professores foram incluídos. Os professores são apoiados por professores assistentes e por pós-doutorandos da Divisão de Estudos Críticos da Escola Superior de Cinema. Todos têm de participar de uma oficina de verão ministrada por pós-doutorandos, mas também, e talvez esse ponto seja o mais importante, por professores que já ensinaram no programa antes. Pares mentores funcionam em todos os níveis. $\mathrm{O}$ objetivo é ajudar os professores que estão chegando a repensarem o conteúdo de seus cursos. Pedimos que eles nos digam claramente o que querem ensinar e, então, tentamos ajudá-los a descobrir como a linguagem multimidiática pode promover tal objetivo. Também os convidamos a avaliar suas pesquisas em andamento para verificar como a linguagem multimidiática pode oferecer novas perspectivas ou, pelo menos, sugerir uma nova abordagem às suas atuais preocupações, Esperamos com isso que eles façam uma relação mais direta de seus trabalhos de pesquisa com suas aulas. Nas oficinas, eles devem ser os autores de seus próprios projetos, que devem ser específicos de suas disciplinas. Ao mesmo tempo, eles são convidados a repensar o conteúdo de seus cursos a fim de incluir projetos que envolvam multimídia.

Os cursos que já participaram do nosso programa variam de estudos de gênero a física quântica, de estudos eslavos a filosofia. Os projetos variam muito até mesmo em suas abordagens. Alguns se estruturam em torno de sites Web, como no curso de eslavo, no qual os alunos desenvolveram um site que permitia aos visitantes navegarem no texto de Crime $e$ Castigo através de mapas de São Petersburgo. Um outro site de aluno, criado em uma disciplina de literatura asiática americana, explicava o romance Guerreira Mulher [Woman Warrior], examinando o abuso perpetrado contra mulheres, desde amarrar os pés até o uso de espartilhos, usando imagens de cultura popular que inculcavam essas práticas nos sistemas de crenças. Outras turmas trabalharam com bases de dados, como no curso sobre "Cultura dos anos 60", em que os alunos coletaram histórias orais. O professor pode usar esse material tanto em suas próprias pesquisas quanto em suas aulas futuras. Mais recentemente, temos visto a criação de elaborados jogos interativos.

Nos últimos anos, tenho me convencido de que a linguagem multimidiática em rápido desenvolvimento - a linguagem da tela - pode trazer novas e importantes abordagens para pesquisa, publicação e ensino. Agora, temos simplesmente que aceitar o desafio de abraçar essa nova mudança de paradigma que é necessária a fim de trazer esse vernáculo para o meio acadêmico. Felizmente, tenho colegas que concordam comigo. Por exemplo, o Dr. Mark Kann, chefe do departamento de Ciência Política da USC, recentemente declarou: "Parece-me que, em algum momento, a expressão por meio de multimídia vai ser como a escrita: é algo que a gente não vai deixar de aprender antes de sair da faculdade. As crianças 
são muito sofisticadas quando navegam em computadores e surfam na internet. Acho que, muito em breve, elas vão ter de ser igualmente sofisticadas ao se expressarem através das mídias. E eu não ficaria tão surpreso se, em algum momento, começasse a aparecer nas universidades um programa de linguagem multimidiática que fosse equivalente ao de escrita para calouros. Tal programa se tornará uma exigência para se concluir a graduação."

O conceito de uma linguagem composta de elementos que não são palavras e textos não é nem fundamentalmente novo e nem especialmente revolucionário. Na verdade, esse conceito é uma evolução das ideias e práticas que estão conosco desde os esforços ancestrais para deixar registros e contar histórias. A tecnologia está simplesmente possibilitando esses modos alternativos de comunicação que penetram em nossas vidas mais diretamente e de formas mais poderosas.

\section{REFERÊNCIAS BIBLIOGRÁFICAS}

BROWN, J. S. (2001). "Learning in the Digital Age," in Maureen Devlin, Richard Larson, and Joel Meyerson, Orgs., The Internet and the University: Forum 2001 (Boulder, Colo.: EDUCAUSE and The Forum for the Future of Higher Education, 2002), 71-72, http://www.educause.edu/forum/ ffpiu01w.asp (Acesso em 21/01/2003).

EISENSTEIN, S. (1957). Film Form. Traduzido e organizado por Jay Leyda. New York: Meridian Books.

MICHELSON, A. (org) (1984). Kino-eye: The Writings of Dziga Vertov. Tradução de Kevin O’Brien. Berkeley: University of California Press.

MANDER, J. (1978). Four Arguments for the Elimination of Television. New York: Morrow.

TOULMIN, S. (1990). Cosmopolis: The Hidden Agenda of Modernity, New York: Free Press.

(2001). University of Michigan, President's Information Revolution Commission Report, April 2001, <http://www. umich.edu/pres/inforev2/> (accessed January 21, 2003).

Recebido: 25/07/2010

Aceito: 28/11/2010 
